\title{
Ethics in the laboratory examination of patients
}

Tarja Nyrhinen and Helena Leino-Kilpi University Central Hospital of Turku, and University of Turku, Finland respectively

\begin{abstract}
Various value problems are connected with the clinical examination of patients. The purpose of this literature review is to clarify: 1) in which patient examinations ethical problems are generally found;2) what kind of ethical problems are found in the different phases of the examination process, and 3) what kind of ethical problems are found in connection with the use of examination results. Genetic testing, autopsy, prenatal and HIV examinations were ethically the most problematic laboratory examinations. The most problematic phase in the laboratory examination process proved to be the pre-analytic phase. At present the results of laboratory examination are used more and more often for the prediction of diseases. The problems appear when the examination results are used for discrimination and stigmatisation. Because of the lack of empirical ethical research, it is important to chart empirical knowledge about present value conflict situations involved in the laboratory examination process.

(Fournal of Medical Ethics 2000;26:54-60)

Keywords: Ethic; laboratory; test; examination; diagnosis; patient
\end{abstract}

\section{Introduction}

Various value problems arise in connection with the clinical examination of patients. First, conflicts can be caused by different opinions about the risks and benefits of the examination and about the rights and duties of those involved: patients, relatives, professionals, health care organisers and society. Second, the examination of patients involves value dilemmas concerning deeper life convictions. The rights of the deceased and of laboratory patients have also become topics of ethical discussion. ${ }^{12}$

In this article, the examination of patients is described as a process in time in which different professions participate. Ethically problematic situations are described by dividing the examination process into the pre-analytic, analytic and post-analytic phases. The pre-analytic phase includes: 1) deciding to organise the examination;
2) informing the patient and gaining consent; 3) ordering the examination and preparing the patient, and 4) collecting the specimen. The analytic phase consists of: 5) preparing the sample; 6) storing the sample; 7) analysing the results, and 8) verifying the results. The post-analytic phase includes: 9) reporting the results; 10) interpreting the results; 11) informing the patient or relatives of the meaning of the results, and 12) applying the results to patient care. ${ }^{34}$ The use to which the results are put is also considered as an ethical problem outside the examination process as such.

\section{Research questions and data}

The purpose of this review is to clarify:

1. In which patient examinations are ethical problems generally found?

2. What kinds of ethical problem are found in the different phase of the examination process?

3. What kinds of ethical problem are found in connection with the use of examination results?

The literature search was carried out on the Medline-database for the years 1991-1998. (See figure 1). In the search the keyword "ethic" was used in connection with "examination", "testing", "investigation", "diagnostic" and "autopsy". The total number of scientific publications found to contain terms related to human examination and ethics was 337, of which 270 (76 \%) were classified as "journal" publication type. Articles on animal examination and the publication type "editorial", "news", "comment", "meeting", "report" and "letter" were excluded. A first analysis of the types of examinations in which ethical problems arose was performed by classifying the articles on the basis of the mesh words. Articles that belonged to several classes were categorised on the basis of the central concept of the title. The second phase of the analysis was confined to the four laboratory examination types in which most ethical problems occurred. These articles were 


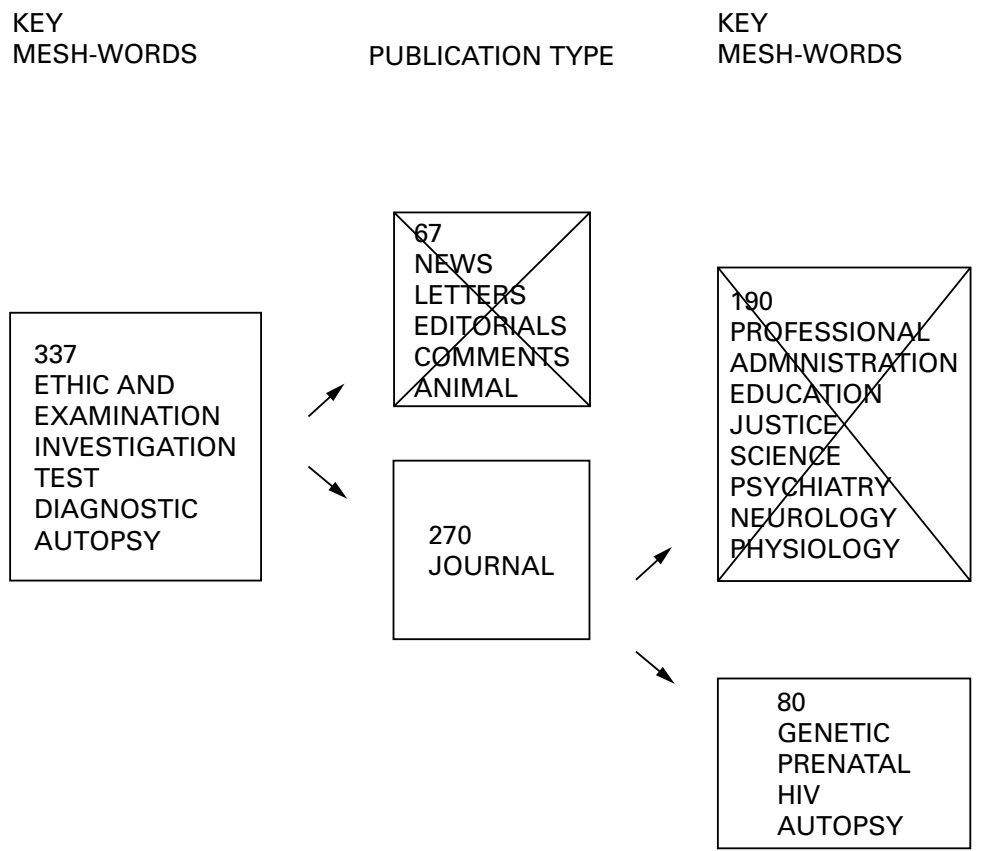

analysed on the basis of the ethical problems arising in different phases of the examination process. In the third phase the same articles were analysed by examining the type of ethical problems that occurred in the use of the examination results. In this phase the data consisted of 80 articles.

Academic articles about the examination process and the ethics of patient care deal with widely different fields of science. The main theme of ethics articles was invasive laboratory examinations in which tissues and blood are analysed; this was the case in a third of the articles (80). In twothirds of the articles ethics was examined from the legal, professional, educational, administrational, psychiatric and scientific research point of view (190). The authors of most of the articles were medical. Ethics was examined from the nursing point of view in six articles. ${ }^{5-10}$ "Philosophy" as a keyword appeared in only six articles, and the terms "values" and "ethical principles" were not found in any, but ethical theories were referred to in one article. One fifth of the 270 articles were of the "review" type and the rest various kinds of committee reports, conclusions of expert panels, and comments. Only a few articles presented research based on empirical data.

\section{Ethical problems in laboratory examinations}

Ethical questions arising from the clinical examination of patients mostly concerned invasive laboratory examinations. Genetic testing, autopsy, prenatal and HIV examinations were ethically the most problematic laboratory examinations (80 articles). Ethical problems in other laboratory examination types, for example physiological and neurophysiological examinations, were mentioned rarely, in only seven articles.

The most problematic types of laboratory examination proved to be genetic examinations and autopsies. The most general problems of genetic examinations concerned maintaining confidentiality, protecting the autonomy of the subjects and questions of justice. The confidentiality problems were in connection with the predictive value and diagnostic errors of the tests. Autonomy problems were connected with patient counselling, and justice problems with the justification of genetic screening. The most common problems with autopsies concerned respecting the autonomy of the deceased and relatives, mainly in connection with informed consent and decision making. Confidentiality was especially problematic in connection with the disclosure of the true cause of death and with giving expert testimony. Both in genetic examinations and in autopsies the 
ethical principle of beneficence raises problems Application of the beneficence principle was considered in connection with risk factor analyses of genetic examinations and when giving support to the bereaved family coping with grief. The ethical problems in prenatal examinations mostly concentrated on confidentiality, and the ethical problems of HIV tests on autonomy and obtaining informed consent.

\section{Ethical problems in different phases of the examination process}

ETHICAL PROBLEMS IN THE PRE-ANALYTIC PHASE

Two thirds of the ethical problems (53 articles) mentioned concerned the pre-analytical phase. The most ethically problematic sub-phases in genetic, HIV, prenatal and autopsy examinations were 1) organising and selecting the examination; 2) informing the patient and gaining consent and, 4) collecting the specimen.

\section{Organising and selecting the examination}

The responsibility of those organising and performing genetic tests to inform the participants about the possible benefits and risks of the examination to the individual, to future generations and to society as a whole, was emphasised..$^{5112}$ The problems of prognosis and risk calculation are more complex when dealing with symptom-free patients. ${ }^{11}$ The rapid growth of DNA-based tests raises complex questions about how to integrate them efficiently into clinical medicine and about the medicolegal consequences of rapidly shifting standards of practice. $^{12}$ The human genome project has brought latent ethical problems in commercial health insurance to the surface. ${ }^{13}$

HIV tests performed on health care professionals and prisoners can lead to loss of privacy and autonomy. ${ }^{14-16}$ There is debate over the justification and costs of arranging HIV testing of employees as a means of preventing the spread of tuberculosis. ${ }^{17}$ Prenatal HIV tests were especially controversial. They were seen as problematic from clinical, legal, ethical, economical, scientific, theological, social and cultural points of view. ${ }^{18-20}$ Strategies for test organisation in all the areas previously mentioned include sub-areas to be considered in relation to prenatal HIV testing. ${ }^{18}$

Autopsy requires consideration of ethical principles such as beneficence, non-maleficence, autonomy and justice in order to obtain the optimal benefit from the procedure. The opinions of various parties involved also must be taken into consideration, ie the deceased, the relatives, the coroner, clinicians, medical students, the legal authorities and researchers. ${ }^{21}$ Autonomy is some- times described as if only two parties are involved: the relatives and other interested parties. But other questions must be taken into consideration: the costs of autopsy, legal requirements to consider the wishes of the relatives, the need for autopsy, the possible benefit to epidemiological research, the integrity of the deceased, autopsy on persons with brain death, various cultural and religious viewpoints, the value of respecting the dead and the social views of the deceased, as well as the application of the ethical principles of autonomy and beneficence to autopsy and organ transplant. ${ }^{22} 23$

In the emergency department it has been a common practice for doctors to learn life-saving technical skills on patients who have recently died. This practice has lately been criticised on religious, legal, and ethical grounds, and has fallen into disuse in many hospitals. There should be clear ethical and legal guidelines as to whether doctors in emergency departments should practise minimally invasive procedures on the newly dead. ${ }^{24}$

Informed consent

The presupposition before genetic testing takes place is completely informed consent in which the risks and benefits are made clear. It is the counsellor's responsibility to make sure that the examinee is psychologically prepared to handle the emotional distress which may occur as the consequence of the testing. ${ }^{25}{ }^{26}$ For example, in the predictive genetic test for Alzheimer's disease the problem has been to provide counselling that allays prejudice and fears of stigmatisation. ${ }^{11}$

In prenatal examinations, for example in utero HLA-typing, the informed consent of mothers can cause problems, for example, when the blood sample is seen as belonging to the neonate, a "third party", on whose behalf the mother gives her consent. ${ }^{27}$ The need to obtain informed consent for banking and examining blood samples taken from the umbilical cord has attracted consensus among experts in blood banking, bone marrow transplantation, ethics, law, obstetrics, paediatrics, social science and anthropology. They state that the process of obtaining informed consent for collection of umbilical cord blood should begin before labour and delivery and that well-informed parents are best positioned to make a decision consistent with their values, goals and resources. ${ }^{28}$ Perinatal necropsy is an important investigation following fetal or neonatal loss. Legal requirements on registration require consent before necropsy can proceed in some of these babies, but ill-defined grey areas are open to legal and ethical difficulties, and obtaining consent for a necropsy can cause distress to parents at a time of grief and bereavement. ${ }^{29}$ In emergency depart- 
ments performing minimally invasive procedures on newly dead patients can be ethically and legally problematic, again for example when obtaining consent from relatives. ${ }^{24}$

Debate has raged over whether HIV testing for prison inmates should be mandatory, and whether to segregate those who test positive. AIDS activists, worried about confidentiality and segregation, have discouraged HIV testing of symptomfree inmates. More recently, the main emphasis has been on ways to increase voluntary testing. Ideally, HIV testing and counselling should be carried out by non-correctional staff. Trust is critical to informed consent, and the relation between staff and inmates is inherently distrustful. Inmate confidentiality should be maintained, although in many states in the USA this is not possible. Disincentives to testing should be examined and minimised. Moreover, testing must be followed up with counselling and education, and with good medical care. ${ }^{16}$ Despite published recommendations for the widespread implementation of prenatal HIV counselling and testing, in many instances in the USA there has been a failure of clinicians to enact such guidelines. Clinician attitudes, beliefs, HIV-related knowledge, involvement with HIV-infected patients and training in counselling skills, as well as institutional and patient characteristics, influence whether clinicians encourage their patients to consent to HIV testing. Time and shared language are the best predictors of physician-conducted HIV risk assessment and counselling. ${ }^{18}$

\section{Specimen collection}

In prenatal diagnosis chorionic villus sampling and amniocentesis sampling were the only areas to which ethical questions were attached in the literature reviewed. ${ }^{19}{ }^{30}$ The justification for sampling fetal tissue is seen to differ from the ethical justification for abortion, and for that reason it should always be viewed in relation to benefit to the patient. ${ }^{31}$ In infertility examinations and advanced reproductive technologies sperm collection is considered as ethically problematic. Sperm collection in the laboratory by masturbation may not be acceptable on religious grounds and in such cases the semen specimen should be collected through coitus using a pre-treated condom. ${ }^{32}$

\section{ETHICAL PROBLEMS IN THE ANALYTIC PHASE}

Less than one tenth (seven) of the 80 articles mentioned problems in the analytic phase, ie 6 ) storing the sample and 8) verifying the results. These were usually involved with the banking or storing of genetic samples and the emotional distress caused by possible false positive results.
Sample storage

With prenatal examinations the problems are associated with administrative and practical issues related to establishing banks for storing cord blood. ${ }^{27}$ Banking umbilical cord blood has several different purposes. First, parental participation in autologous umbilical cord blood banking programmes may be fuelled less by the weight of scientific evidence than by parents' desire to protect their children. Second, banking umbilical cord blood for autologous use is associated with even greater uncertainty than banking for allogenic use. If autologous use is demonstrated over time to be safe and effective, both society and donors will have a stake in how it is banked and whether it is treated as a commodity. To date, banking of umbilical cord blood for autologous use has been a private, unregulated, entrepreneurial venture. More data are needed to ensure that recruitment for banking and use are equitable. Third, marketing practices for umbilical cord blood in the private sector need close attention. Thus, even if banking creates no direct physical risks to donors, it may produce significant social risks related to privacy. Under new programmes, banked umbilical cord blood will be linked to demographic information about each donor. The primary purpose of maintaining this linkage is to allow unsafe units to be identified at some future date. Secure linkage of stored umbilical cord blood to the identity of the donor should be maintained. Such arguments are based not only on precedent but also on safety. ${ }^{28}$

\section{Result analysis and verification}

The weak reliability and specificity of HIV tests and carelessness on the part of those performing the test can cause false positive or false negative results and emotional distress for the test participant. This can be seen as sufficient grounds for legal claims, which traditionally can be based, for example, on the general duty to avoid negligent infliction of emotional distress. ${ }^{193}$

In medicolegal autopsy it is important correctly to identify postmortem artefacts. Autopsy results are not always very reliable; various injuries labelled as antemortem may later be found to be postmortem. ${ }^{34}$

ETHICAL PROBLEMS IN THE POST-ANALYTIC PHASE One fourth (20) of the 80 articles were concerned with the post-analytic phase, especially in the subphase of 10) interpreting the results, 11) informing the patient or relatives of the meaning of the results. Ethically the most problematic examinations in this respect were genetic and HIV examinations. 
Reporting results

With HIV infection and stigmatising conditions the need for confidentiality about the patient's medical condition has long been recognised. The obligation to maintain confidentiality continues after the death of the patient. At the same time, there may be public health concerns that justify limited disclosure of a deceased person's human immunodeficiency virus status. ${ }^{35}$

Autopsies are also frequently used to evaluate the accuracy of cause-of-death information on death certificates. Unauthorised disclosure of HIV status or other medical information after death may affect the perceptions of others about the deceased patient or cause speculation, suspicion, or judgment regarding the character of the deceased. The effect of unauthorised disclosure would violate the patient's privacy and best interests. The privacy of the deceased's family or friends is also violated by unauthorised disclosure. There is a significant amount of disagreement between cause-of-death information on death certificates and the cause-of-death information revealed at autopsies. ${ }^{35}$ The physician's responsibility for disclosure of iatrogenic damage has also given rise to discussion. ${ }^{36}$

In prenatal testing, reporting the results regarding umbilical cord blood can be an ethical problem. Secure linkage and confidentiality, again should be maintained, especially in relation to insurance companies and employers. ${ }^{25} 28$

Informing the patient of the significance of the result In predictive testing for Huntington's disease participants were videotaped during their pre- and post-test counselling sessions, as well as when the results were given. Changes that accompanied the receipt of decreased risk suggested that counselling as well as genetic information led the participants through a rite of passage. The most significant changes seemed to be in relation to other family members. ${ }^{26}$ The issue is additionally complex in genetics because the genetic test involves families, not just individuals. A person who tests positive for a predictive or predisposing trait immediately reveals information about the possible risk that first-degree relatives are also affected. ${ }^{5}$ In diagnostic testing for Alzheimer's disease, a substitute decision maker will often be involved and an unavoidable result is that some of the related substitute decision makers will receive results which may have, or be mistaken to have, predictive value. Substitute decision makers must therefore be included in genetic counselling, and the psychosocial effects of their participation must be evaluated. ${ }^{26}$
In genetic testing it is important for women who are not gene carriers to know that they still need to go for screening. Individuals need to be helped to cope with their risk status, whether it is actual high risk or perceived high risk. Positive screening results cause negative emotional effects, but studies indicate that over time, regardless of their risk levels, individuals do learn how to cope with and adapt to their risk status so that negative psychological sequelae are minimised. ${ }^{25} 26$ In prenatal genetic diagnosis, for example in umbilical cord testing, the discovery of disease has different implications for different mothers. ${ }^{27} 31$

\section{Ethical problems in the use of examination results}

The ethical problems of each phase have been examined here in connection with patient care. But in most of the articles analysed more comprehensive ethical questions in human examination were also examined. The results of laboratory examination are now used increasingly for the prediction of diseases, and this is likely to alter fundamentally the investigative balance between the hospital and the community. ${ }^{37}$ Problems arise especially when the examination results are used for discrimination, stigmatisation, determining of an insurance premium or when searching for the cause of death. ${ }^{12}$ Preventive diagnosis using molecular methods will change the scientific basis of prognostics. At the same time, it will change the ethical dimensions of relations among patients and other providers of care. Novel prognostic features of molecular medicine are illustrated by the identification of genes associated with susceptibility to common diseases. We still struggle to find the right words for the status conferred by the presence of the genes, calling it "susceptibility", "predisposition", "propensity", "proclivity", and referring to "risk", "potential" and "likelihood". Whatever the term is, we are increasing the ability to inform a patient that he or she will suffer from a disease of greater or lesser severity, at some time in the future, with some probability, and in some cases almost with certainty. What is the ethical meaning of this sort of prognostic information ? $^{38}$

\section{Conclusion}

The most ethically problematic examination type was genetic examination, but ethical problems were also mentioned in other invasive examinations, for example, autopsy, prenatal and HIV examinations. Problems were divided fairly equally with reference to all the bioethical principles, but with the main stress on confidentiality and autonomy, since such examinations often threaten the patient's integrity. 
The most problematic phase in the laboratory examination process proved to be the pre-analytic phase, in which patient autonomy and confidentiality figured especially in the sub-phases 1) deciding to organise the examination; 2) informing the patient and gaining consent and, 4) collecting the specimen. In sub-phase 3) ordering the examination and preparing the patient, no problems were mentioned. The reason for this could be that these activities might also be considered as belonging to the previous or following sub-phase. The number of ethical problems reported in the analysis phase was much smaller, mainly problems in the banking of genetic samples. It is worth noting that the interpretation of results in sub-phases was not seen as problematic, even though laboratory medicine is a rapidly advancing field and many special examination types need expert skills for the interpretation of the results. Since health care resources at present appear insufficient even for patient care, it is surprising that ethical questions concerning the last sub-phase 12), applying the results to patient care, received no attention. Ethical problems in the use of examination results proved to be mostly value conflicts between the individual and society.

When considering the validity of this literature review, it must be remembered that the review data comprised only articles dealing with examinations analysed in a laboratory. Administrative and legal articles were not taken into consideration, so problems involving society and organisations were mentioned less often. The same applies to problematic situations between different professional groups. It is also probable that more varied and more detailed information could have been obtained by performing the literature search without "ethic" as a keyword. Practical ethical problems will have been examined using empirical methods without connecting the concept "ethic" to the problem.

The literature reviewed here clearly reveals which examinations and which phases of these examinations are ethically most problematic, as well as identifying the problems involved. This can be seen as evidence that we need more discussion concerning ethical values in patient examination and concerning the use of examination results. Because of rapid advances in laboratory examinations and the lack of empirical ethical research, it is important to chart empirical knowledge about present value conflict situations involved in the laboratory examination process in health care. Identification of the ethical conflicts would help to develop procedures which would take the views of patients and different professional groups more comprehensively into consideration. At the same time it would advance the development of legitimate and ethically just examination procedures.

Tarja Nyrhinen, MNSc, is a Medical Laboratory Technologist at the University Central Hospital of Turku. Helena Leino-Kilpi, PhD, RN, is Professor of Nursing Science at the University of Turku, Faculty of Medicine, Department of Nursing. Address for correspondence: Tarja Nyrhinen, Medical Laboratory Technologist, University Central Hospital of Turku, Central Laboratory, Department 931, Kiinamyllynk 4-8, 20520 Turku, Finland.

\section{References}

1 Leino-Kilpi H, Nyrhinen T, Katajisto J. Patients' rights in laboratory examinations: do they realize? Nursing Ethics 1997;4:451-64.

2 Veress B. Reduced number of autopsies. A threat against a source of knowledge and legal rights. Lakartidningen 1994;91: 2685-7.

3 Gruder WG, Narayanan S, Wisser H, Zawta B. Samples: from the patient to the laboratory. The impact of pre-analytical variables on the quality of laboratory results. Darmstadt: Git Verlag, 1996. 4 Barr JT, Schumacher GE. The total testing process applied to therapeutic drug monitoring. In: Schumacher GE, ed. Therapeutic drug monitoring. Norwalk, Connecticut: Appleton \& Lange, 1995:47-82

5 Raines DA. Ethical implications of genetic testing. Ethics for Nursing Practice 1998;33:275-87.

6 Bolus J, Flanagan C, Martin-Urban J. Protecting a teen patient's privacy. Advanced Nurse Practice 1997;5:15.

7 Downes J. The ethical dilemmas of mandatory prenatal and newborn HIV testing. Nursing Connections 1995;8:43-50.

8 Hoffmann DE, Wulfsberg EA. Testing children for genetic predispositions: is it in their best interest? fournal of Law, Medipredispositions: is it in their best
cine and Ethics 1995;23:331-44.

9 Howard G. Medical examinations: law, ethics and good practice. Occupational Health London 1992;44:72-4.

10 Beck DM. Mandatory HIV testing for health care workers: is it Beck DM. Mandatory HIV testing for
ethical? Nursing Forum 1992;27:9-14.

11 Post SG, Whitehouse PJ, Binstock RH, Bird TD, Eckert SK, Farrer LA, et al. The clinical introduction of genetic testing for Alzheimer's disease. An ethical perspective. Fournal of the American Medical Association 1997;277:832-6.

12 Reilly P. Physician responsibility in conducting genetic testing. Fournal of the National Cancer Institute 1995;17:59-61.

13 Murray TH. Ethics, genetic prediction, and heart disease. American fournal of Cardiology 1993;72:80D-4D.

14 Newell A, Barton SE. Testing healthcare staff for infection with HIV and hepatitis: logistic and ethical considerations. fournal of Clinical Pathology 1995;48:885-9.

15 Shorr AF. Health care workers, patients, and HIV: an analysis of the policy and ethical debate. Pharos of Alpha Omega Alpha Honor Medical Society 1995;58:7-13.

16 Diamond J. HIV testing in prison: what's the controversy? Lancet 1994;344:1650-1.

17 Bayer R, Dubler NN, Landesman S. The dual epidemics of tuberculosis and AIDS: ethical and policy issues in screening and treatment. American Fournal of Public Health 1993;83:64954.

18 Minkoff H, Willoughby A. The future of prenatal HIV testing. Acta Paediatrica Supplement 1997;421:72-7.

19 Pergament E, Bonnicksen A. Preimplantation genetics: a case for prospective action. American fournal of Medical Genetics 1994;52:151-7.

20 Kaufmann RA, Morsy M, Takeuchi K, Hodgen GD. Preimplantation genetic analysis. Fournal of Reproductive Medicine 1992;37:428-36.

21 Westrin CG, Nilstun T, Smedby B, Haglund B. Epidemiology and moral philosophy. Fournal of Medical Ethics 1992;18:193-6.

22 Nilstun T. The Swedish Society for Medical Ethics. The benefits of an autopsy for the society must be confronted with the respect for the integrity of the deceased. Lakartidningen 1991;88:1603-4. 
23 Mittleman RE, Davis JH, Kasztl W, Graves WM Jr. Practical approach to investigative ethics and religious objections to the autopsy. Fournal of Forensic Sciences 1992;37:824-9.

24 Iserson KV. Postmortem procedures in the emergency department: using the recently dead to practise and teach. fournal of Medical Ethics 1993;19:92-8.

25 Kash KM. Psychosocial and ethical implications of defining genetic risk for cancers. Annals of the New York Academy of Sciences 1995;30:41-52.

26 Burgess MM. Ethical issues in genetic testing for Alzheimer's disease: lessons from Huntington's disease. Alzheimer Disease Associated Disorders 1994;8:71-8.

27 Burgio GR, Locatelli F. Transplant of bone marrow and cord blood hematopoietic stem cells in pediatric practice, revisited according to the fundamental principles of bioethics. Bone Marrow Transplant 1997;19:1163-4.

28 Sugarman J, Kaalund V, Kodish E, Marshall MF, Reisner EG Wilfond BS, et al. Working Group on Ethical Issues in Umbilical Cord Blood Banking. Ethical issues in umbilical cord blood banking. Fournal of the American Medical Association 1997;278 938-43.

29 Khong TY. Ethical considerations of the perinatal necropsy. fournal of Medical Ethics 1996;22:111-14.

30 Auerbach AD. Umbilical cord blood transplants for genetic disease: diagnostic and ethical issues in fetal studies. Blood Cells 1994;20:303-9.
31 Stranc LC, Evans JA, Hamerton JL. Chorionic villus sampling and amniocentesis for prenatal diagnosis. Lancet 1997;349: 711-14.

32 Mastroyannis C. Gamete intrafallopian transfer: ethical considerations, historical development of the procedure, and comparison with other advanced reproductive technologies. Fertility and Sterility 1993;60:389-402.

Fertility and Sterility 1993

Mazur DJ. Judgmental psychology, law, and ethics. Medical Decision Making 1998;18:126-7.

34 Mirza FH, Makhdoom PA. Importance of correct interpretation of postmortem artifacts in medicolegal autopsies. Fournal of the Pakistan Medical Association 1998;48:49-50.

35 American Medical Association: Council on Ethical and Judicial Affairs. Confidentiality of human immunodeficiency virus status on autopsy reports. Archives of Pathology and Laboratory Medicine 1992;116:1120-3.

36 Madea B, Waider H. Responsibilities and value of autopsy. The physician's responsibility for disclosure of iatrogenic damage. physician's responsibility for disclosure of iatrogenic damage. Fortschritte der Medizin: Internd 1995;113:247-9.

37 Wierzbicki AS. Laboratory investigations by DNA amplification: from research to practice. Annals of Clinical Biochemistry 1998;35:5-11.

38 Jonsen AR, Durfy SJ, Burke W, Motulsky AG. The advent of the 'unpatients'. Nature Medicine 1996;2:622-4.

\section{News and notes}

\section{3th World Congress on Medical Law}

The World Association for Medical Law is to hold its 13th Congress on Medical Law in Helsinki, Finland from 6-10 August 2000 .

Main topics of the scientific programme are: Quality of and priorities in health care: ethics, law and policy; Status and rights of patients; Health care personnel; Liability and enforcement: forensic medicine; Forensic medicine and psychiatry; Biomedicine and human rights; Human dignity and the beginning and end of life.

For further information please contact: Pirkko Kuorehjarvi, Congress Manager: tel: + 35893967 2073; fax: + 35893967 2030; email: pirkko.kuorehjarvi@stakes.fi; website: http:// www.stakes.fi/medlaw

\section{News and notes}

\section{Journal of Medical Ethics - http://www.jmedethics.com}

Visitors to the world wide web can now access the fournal of Medical Ethics either through the BMJ Publishing Group's home page (http:/ www.bmjpg.com) or directly by using its individual URL (http://www.jmedethics.com). There they will find the following:

- Current contents list for the journal

- Contents lists of previous issues

- Members of the editorial board

- Subscribers' information

- Instructions for authors

- Details of reprint services.
A hotlink gives access to:

- BMJ Publishing Group home page

- British Medical Association website

- Online books catalogue

- BMJ Publishing Group books.

The web site is at a preliminary stage and there are plans to develop it into a more sophisticated site. Suggestions from visitors about features they would like to see are welcomed. They can be left via the opening page of the BMJ Publishing Group site or, alternatively, via the journal page, through "about this site". 